\title{
The effect of e-health interventions promoting physical activity in older people: a systematic review and meta-analysis
}

\author{
Rick Yiu Cho Kwan ${ }^{1 *}$, Dauda Salihu', Paul Hong Lee², Mimi Tse', Daphne Sze Ki Cheung ${ }^{1}$, \\ Inthira Roopsawang ${ }^{3}$ and Kup Sze Choi ${ }^{2}$
}

\begin{abstract}
Introduction: The objectives of this review paper were to synthesize the data from randomized controlled trials in the literature to come to a conclusion on the effects of e-health interventions on promoting physical activity in older people.

Methods: The Medline, CINAHL, Embase, PsycINFO, and SportDiscus databases were searched for articles about studies that 1) recruited subjects with a mean age of $>50$ years, 2) tested e-health interventions, 3) employed control groups with no or less advanced e-health strategies, 4) measured physical activity as an outcome, 5) were published between 1st January 2008 and 31st May 2019, and 6) employed randomized controlled trials. The risk of bias in individual studies was assessed using the Physiotherapy Evidence Database scale. To examine the effects of the interventions, variables quantifying the amount of physical activity were extracted. The within-group effects of individual studies were summarized using Hedges $\mathrm{g}$ and $95 \%$ confidence intervals. Between-group effects were summarized by meta-analyses using RevMan 5.0 with a random effect model.

Results: Of the 2810 identified studies, 38 were eligible, 25 were included in the meta-analyses. The within-group effect sizes (Hedges $\mathrm{g}$ ) of physical activity in the intervention group at $\mathrm{T1}$ ranged from small to large: physical activity time (0.12 to 0.84$)$, step counts ( -0.01 to 11.19$)$, energy expenditure ( -0.05 to 0.86$)$, walking time $(0.13$ to 3.33), and sedentary time $(-0.12$ to -0.28$)$. The delayed effects as observed in $\mathrm{T} 2$ and $\mathrm{T} 3$ also ranged from small to large: physical activity time (0.24 to 1.24$)$ and energy expenditure (0.15 to 1.32$)$. In the meta-analysis, the betweengroup effect of the e-health intervention on physical activity time measured by questionnaires, physical activity time measured by objective wearable devices, energy expenditure, and step counts were all significant with minimal heterogeneity.
\end{abstract}

Conclusion: E-health interventions are effective at increasing the time spent on physical activity, energy expenditure in physical activity, and the number of walking steps. It is recommended that e-health interventions be included in guidelines to enhance physical activity in older people. Further studies should be conducted to determine the most effective e-health strategies.

Keywords: Physical activity, E-health, Older people, Step count, Physical activity energy expenditure

\footnotetext{
* Correspondence: rick.kwan@polyu.edu.hk

${ }^{1}$ Centre for Gerontological Nursing, School of Nursing, The Hong Kong Polytechnic University, GH502, 5/F, Block G, Hung Hom, Kowloon, Hong Kong, China

Full list of author information is available at the end of the article
}

C The Author(s). 2020 Open Access This article is licensed under a Creative Commons Attribution 4.0 International License, which permits use, sharing, adaptation, distribution and reproduction in any medium or format, as long as you give appropriate credit to the original author(s) and the source, provide a link to the Creative Commons licence, and indicate if changes were made. The images or other third party material in this article are included in the article's Creative Commons licence, unless indicated otherwise in a credit line to the material. If material is not included in the article's Creative Commons licence and your intended use is not permitted by statutory regulation or exceeds the permitted use, you will need to obtain permission directly from the copyright holder. To view a copy of this licence, visit http://creativecommons.org/licenses/by/4.0/. The Creative Commons Public Domain Dedication waiver (http://creativecommons.org/publicdomain/zero/1.0/) applies to the data made available in this article, unless otherwise stated in a credit line to the data. 


\section{Introduction}

Physical activity is defined as any bodily movement produced by skeletal muscles that results in an expenditure of energy [1]. Physical activity is widely recognized as an effective intervention for reducing mortality and dependence-inducing diseases (e.g., cardiovascular disease, cancers) in older people [2]. Studies have shown that engaging in high-intensity aerobic exercise and 150 min of moderate-intensity exercise promotes cognition in older people with mild cognitive impairment $[3,4]$. The evidence shows that sustainable physical activity at beneficially high levels of intensity is an important element of improved cognitive function. A systematic review of 39 studies showed that physical activity improved the cognitive function of the older participants regardless of their cognitive status [5]. Another systematic review of nine studies showed that for older people physical activity led to improvements in frailty syndrome, body composition, as well as in the performance of many physical functions (e.g., balance, muscle strength) [6].

Physical inactivity, which is associated with an increased risk of morbidity, mortality, and functional dependence, refers to less than $150 \mathrm{~min}$ per week of moderate-tovigorous physical activity (MVPA) [7]. Physical inactivity remains a prevalent global phenomenon, although the beneficial effect of physical activity is known [8]. Unsurprisingly, the prevalence of physical inactivity increases significantly with age, with the proportion of physically inactive older adults being at $67 \%$ globally as reported in a systematic review [9]. Older people were less likely than younger people to engage in regular physical activity [10]. Older people have difficulties achieving the levels of intensity and duration of physical training known to be beneficial [11]. Common barriers to doing so that have been reported in the literature include poor health, a lack of company, lack of interest, lack of skills, and lack of opportunities [12]. Studies have shown that sedentary time (e.g., too much sitting) is also associated with dependence in older people, which is independent of moderate-intensity physical activity [13]. A systematic review showed that even a low dose of moderate-to-vigorous physical activity reduces mortality by $22 \%$ in older people [14]. Therefore, the recent evidence shows that it may be more realistic to reduce the amount of time spent in sedentary activities and increase engagement in light activities to pave the way for older people to engage in more intense exercise [11].

Behavioural change interventions are based on a group of psychosocial theories (e.g., social cognitive theory, the transtheoretical model) that posit that people's behaviours are modifiable when certain factors (e.g., lack of opportunities, lack of skills) are modified [15]. The evidence from many systematic reviews indicates that behavioural change interventions using different behavioural change techniques are effective at motivating different groups of people (e.g., children, obese adults) to increase their levels of physical activity $[16,17]$. However, the size of the effect of conventional behavioural change interventions that are delivered face-to-face is suboptimal in older people $(\mathrm{d}=$ 0.14 ), suggesting that many behavioural change techniques that are effective in young people are not effective in older people [18].

E-health refers to health services that are delivered or enhanced through electronic devices, the internet, and related digital technology [19]. Persuasive technology refers to the use of technology designed to guide users into changing particular attitudes and behaviour, by enhancing the effects of the behavioural change techniques [20]. Persuasive technology employed through electronic devices and internet platforms as a form of e-health intervention was recently used to encourage older people to increase their level of physical activity [21]. E-health interventions have been used extensively in dieting interventions and in interventions to promote physical activity in children and young adults, with promising results, as shown in systematic reviews [20, 22-24]. E-health interventions have also been implemented among older people, and their effects on promoting physical activity have been evaluated in clinical trials. A few systematic reviews have shown that many of them employed different e-health strategies, and many individual trials have shown that many e-health interventions are effective at increasing physical activity but some are not $[25,26]$. The number of trials included in these reviewers was small and therefore the effects of e-health interventions were not concluded in these reviews.

To date, in the current literature, there is a lack of understanding of the effects of e-health intervention on physical activity in older people because the results from different trials were inconsistent and previous systematic reviews could not conclude the effects with a small number of studies identified. Therefore, this review aimed to add knowledge to the literature about the effects by pooling the data reported in the randomized controlled trials. Specifically, the objectives of this study were to identify:

1. The within-group effect of the e-health interventions on physical activity, and

2. The between-group effect of the e-health interventions on physical activity.

\section{Methods}

A systematic review was employed to identify randomized controlled trials evaluating the effects of e-health interventions on promoting physical activity in older people. The reporting format of this systematic review follows the Preferred Reporting Items for Systematic review and Meta-Analysis (PRISMA) guideline [27]. 


\section{Eligibility criteria}

- Population: older people (mean age of the sample > 50 years)

- Intervention: e-health intervention, as defined as using any forms of electronic devices, the internet, and related digital technology to promote health service [19]. In this paper, the health service refers to physical activity promotion.

- Control: not exposed to any e-health interventions or to less advanced e-health interventions

- Outcome: physical activity, as defined as either primary or secondary outcome

- Study design: randomized controlled trial

- Language: English

\section{Sources of information}

We searched the following five databases: Medline, CINAHL, Embase, PsycINFO, and SportDiscus. The databases were searched during the period of 1 January 2019 to 31 May 2019.

\section{Search}

Keywords employed for the search included ["older people" or "older adult" or "elderly" or "senior"] AND ["texting" or "SMS" or "text messaging" or "mobile device" or "mobile health" or "m-health" or "mHealth" or "e-health" or "eHealth" or "internet-based" or "webbased" or "online" or "DVD-based" or "smartphone" or "mobile phone" or "wearable" or "social media" or "computer" or "tablet"] AND ["physical activity" or "exercise" or "step" or "energy expenditure" or "sedentary"]

In the search engines we limited the results to publications with [abstracts] those published during the period of [1 January 2008-31 may 2019] and those with a study design employing [a randomized controlled trial]

We also conducted a hand search to identify potentially eligible articles by checking relevant article references (e.g., eligible articles and relevant systematic reviews) [28].

\section{Study selection}

Identified articles were imported into Clarivate Analytics Endnote X8.0. Duplicates were removed by Endnote, and then by screening the titles, abstracts, and full texts of the articles. The screening of the articles was conducted by two independent authors. In cases where the two authors disagreed over the eligibility of an article, they discussed the article in relation to the eligibility criteria. If they still disagreed, a third author was invited to discuss the issues over with the two authors to ensure that the article fulfilled the eligibility criteria.

\section{Data collection process}

Data were extracted from the full texts of the eligible articles. The selected items of data were copied to a piloted form using Microsoft Excel. Data extraction was conducted by two authors independently. If there were any disagreements over the extraction of data, the two authors invited the third author to discuss the matter according to the pre-defined nature of the data items. In the case of queries, attempts were made to contact the authors of the studies for clarification.

\section{Data items}

To describe the profile of the articles, the following data were extracted: authors, year of publication, age of the subjects (mean and standard deviation), sample size, population characteristics, intervention, controlled condition, outcome, data collection time points, e-health strategies, and targeted physical activity.

To examine the effect of the intervention on the outcome, all variables quantifying the amount of physical activity were extracted (e.g., time spent on physical activity, energy expended on physical activity, step counts, sedentary time). Also extracted were the values of the outcome variables (i.e., mean, standard deviation, and sample size in each group) observed at the baseline (T0), the time point after the completion of the intervention (T1), and the 1st (T2) and 2nd (T3) follow-ups after the completion of the intervention in both the intervention groups and control groups.

\section{Risk of bias in individual studies}

This review employed the Physiotherapy Evidence Database (PEDro) scale to rate the quality of RCTs [29]. The PEDro scale is comprised of 11 dichotomous items (i.e., yes/no) measuring the methodological quality of an RCT (e.g., blinding, concealment, random allocation, baseline similarity, dropout). Except for the first item (i.e., specified eligibility criteria), all 10 items sum up to a total score. The quality of the RCT is rated as excellent (PEDro $=9-10)$, good (PEDro $=6-8)$, fair (PEDro $=4-5)$, or poor $(\mathrm{PEDro}<4)$. We considered studies with a PEDro score of $\geq 4$ to have a minimal standard of methodological quality, and we therefore included only those studies in the quantitative synthesis (i.e., meta-analysis of the effects).

\section{Summary measures and synthesis of the results}

We followed the Cochrane Handbook for Systematic Results of individual studiesReviews of Interventions to handle and analyse the data to run a meta-analysis [30]. Both within-group and between-group effects (i.e., T1 between the intervention and control groups) of individual studies were summarized using Hedges g and a 95\% confidence interval. 
A meta-analysis was performed if three or more studies measured the same outcome and the articles provided the mean and standard deviation of the outcome variables at $\mathrm{T} 1$ (i.e., the time point immediately after the completion of the intervention), in order to understand the immediate between-group effects. A subgroup analysis of the same outcome measured by objective instruments (e.g., pedometers, accelerometers) and subjective instruments (e.g., questionnaires) was conducted separately to minimize heterogeneity among the studies. The results of the meta-analysis are presented through Forest plots using RevMan version 5.0. The $\mathrm{I}^{2}$ index was used to test the heterogeneity of the selected studies. We report a meta-analysis on the outcomes with heterogeneity, which might not be important (i.e., $\mathrm{I}^{2}=0-40 \%$ ), only to ensure the quality of the interpretation of the pooled effects [31]. Random effect models were used because the intervention components in the selected studies were not identical [32], although in all of the studies e-health strategies were used in the interventions.

\section{Results}

\section{Study selection}

As shown in Fig. 1, 2,810 articles were identified in the selected databases: Medline $(n=851)$, CINAHL $(n=$ 289), Cochrane $(n=953)$, PsycINFO $(n=369)$, SPORTDisuc $(n=319)$, and a hand search $(n=29)$. Nine hundred and thirty-nine articles were removed by Endnote and manual screening because they were duplicates,
1807 were removed after screening for title and abstract because they were not eligible, and 26 were removed for ineligibility after a full-text screening. Thirty-eight articles were eligible for a qualitative synthesis. After the extraction of data, 13 articles were not included in the meta-analysis because the risk of bias as rated by the PEDro score was high $(n=2)[33,34]$, the mean and standard deviation at $\mathrm{T} 1$ of both groups were not provided $(n=4)$ [35-38], the effect size or standard deviation were outlined $(n=3)$ [39-41], the outcome variables were measured by fewer than three studies $(n=3)$ [42-44], and the data were from a preliminary analysis, which duplicated data in another study reporting the final analysis $(n=1)$ [45]. In the end, 25 articles were included in the meta-analyses of different outcomes.

\section{Study characteristics}

As shown in Table 1, 38 eligible articles were on randomized controlled trials evaluating the effects of e-health interventions on physical activity outcomes over a total population of 11,194 people, whose mean age ranged from 50.8 to 82 years. The majority of the studies targeted healthy $(n=25,65.8 \%)$, physically inactive $(n=21,55.5 \%)$ older people. Apart from healthy subjects, the remaining studies recruited subjects with different health conditions, including obesity/overweight, cardiac diseases, COPD, obstructive sleep apnoea, diabetes, rheumatoid arthritis, Parkinson's disease, and cancer.

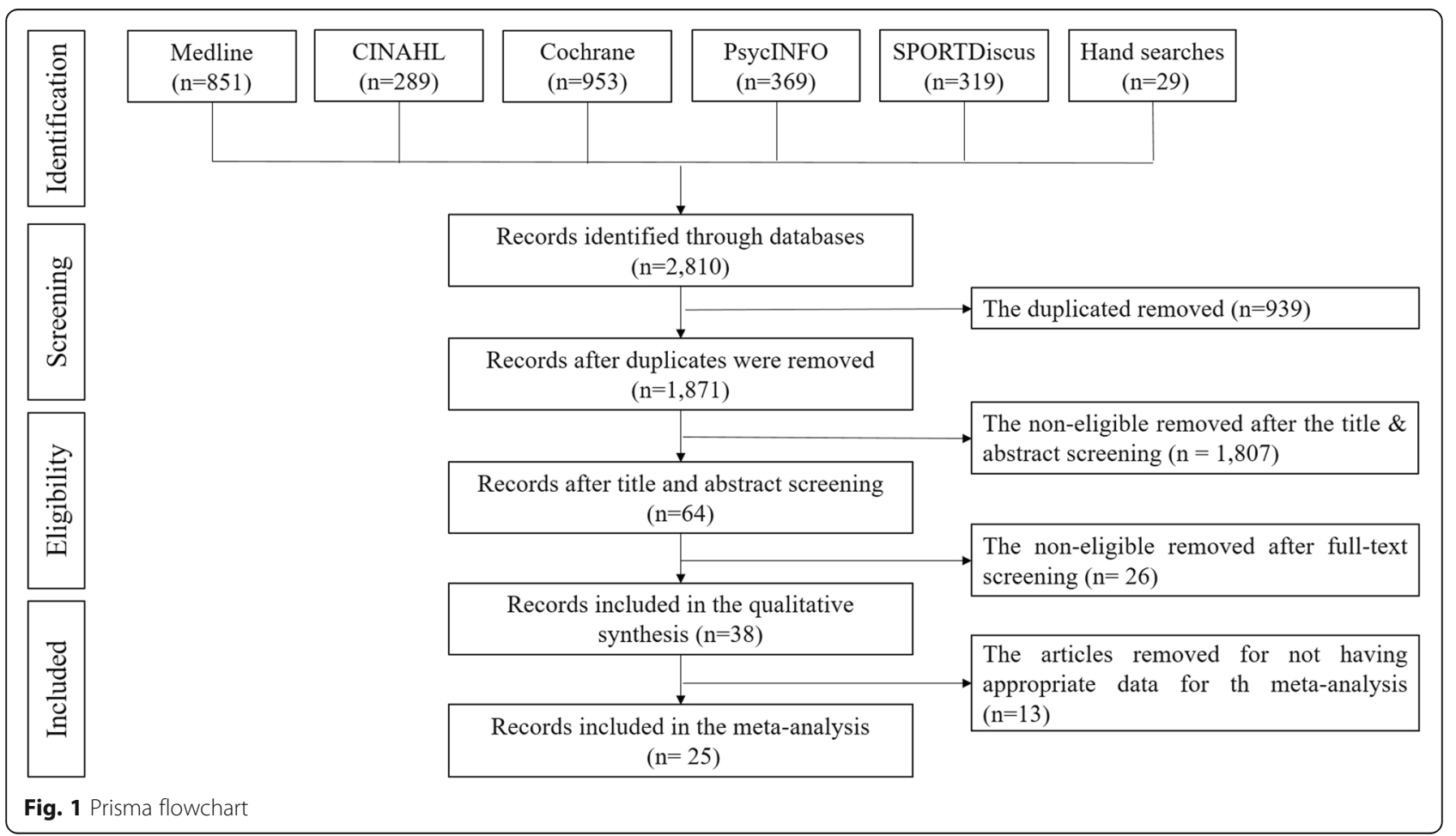




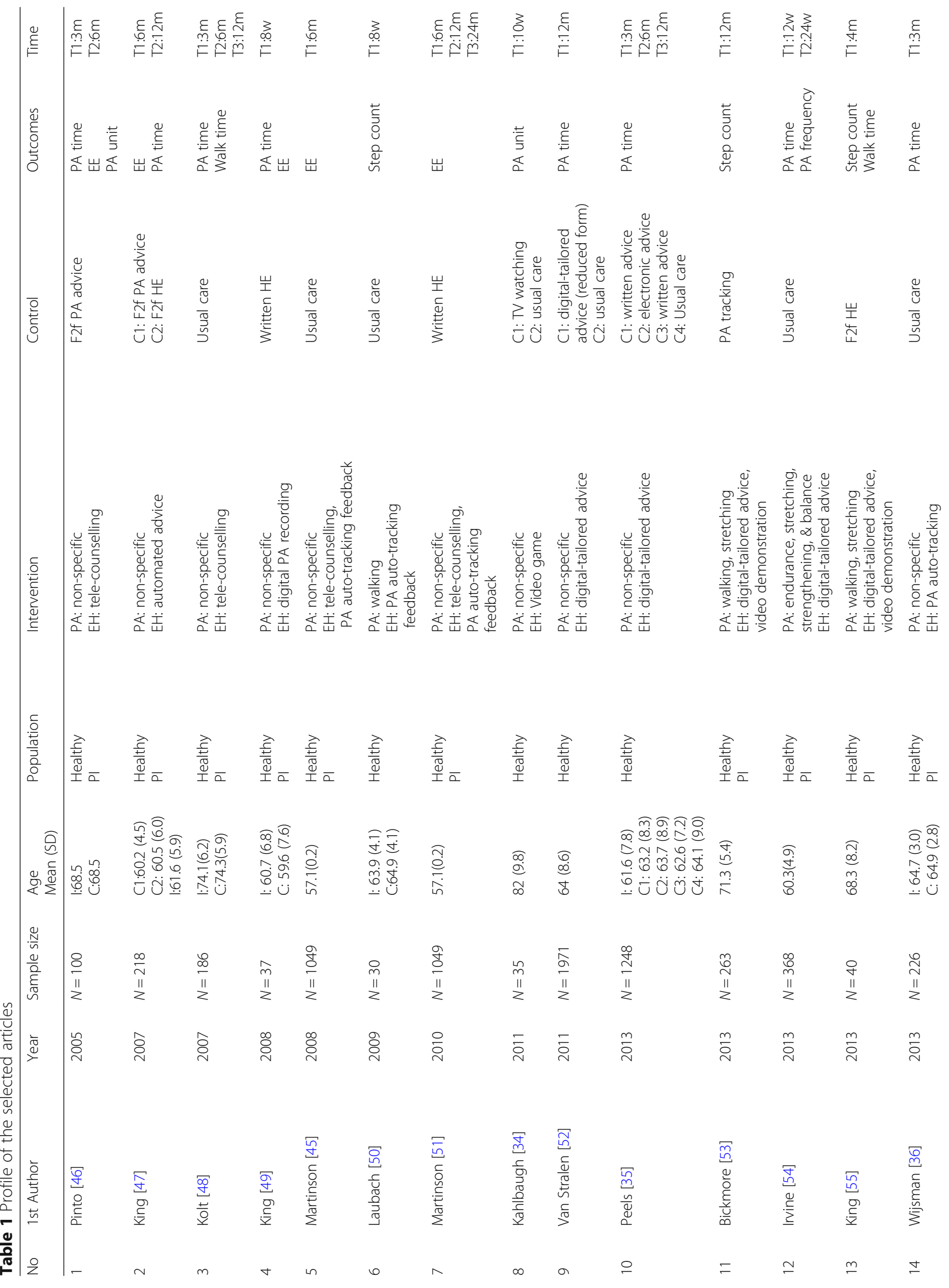




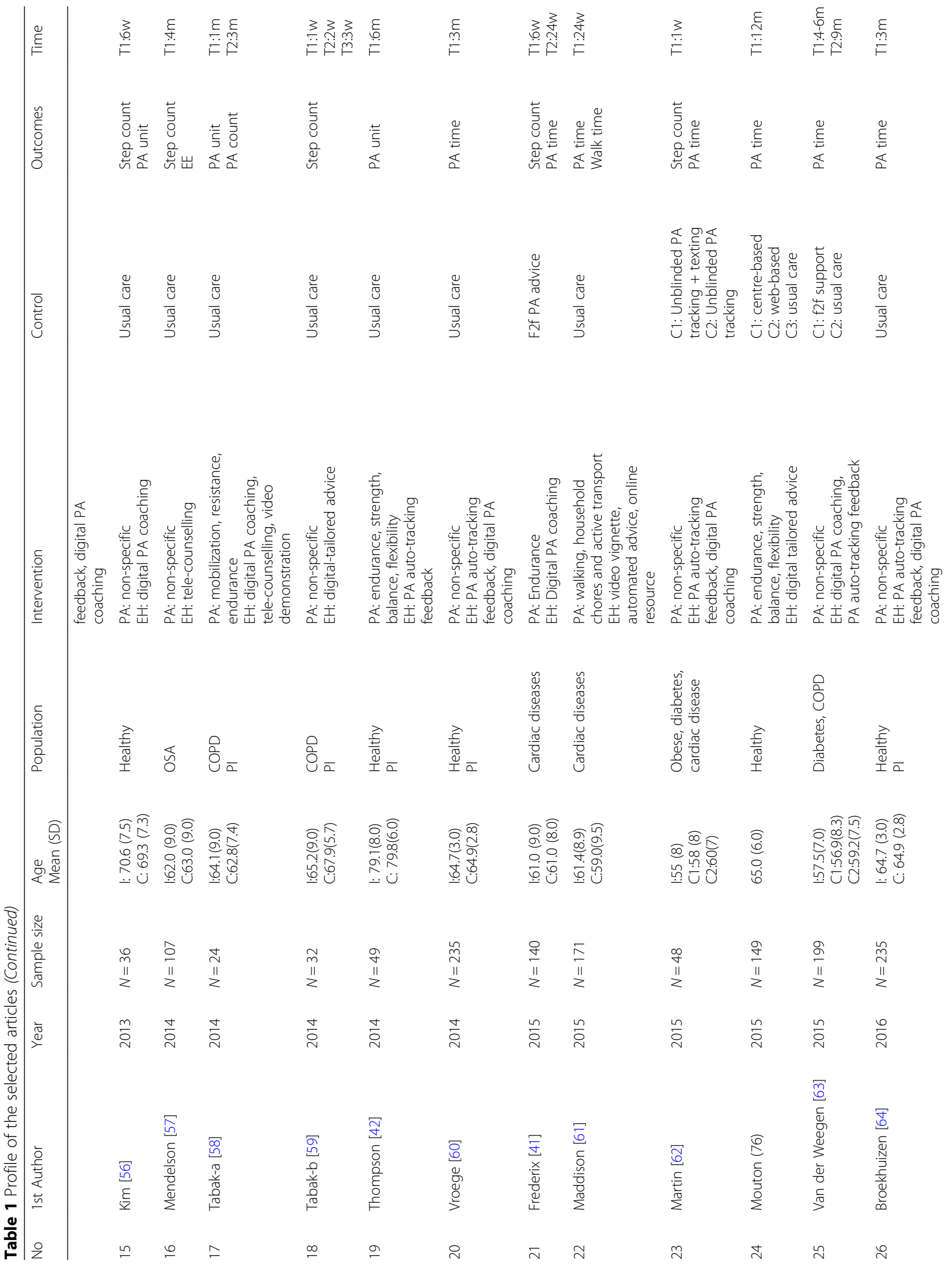




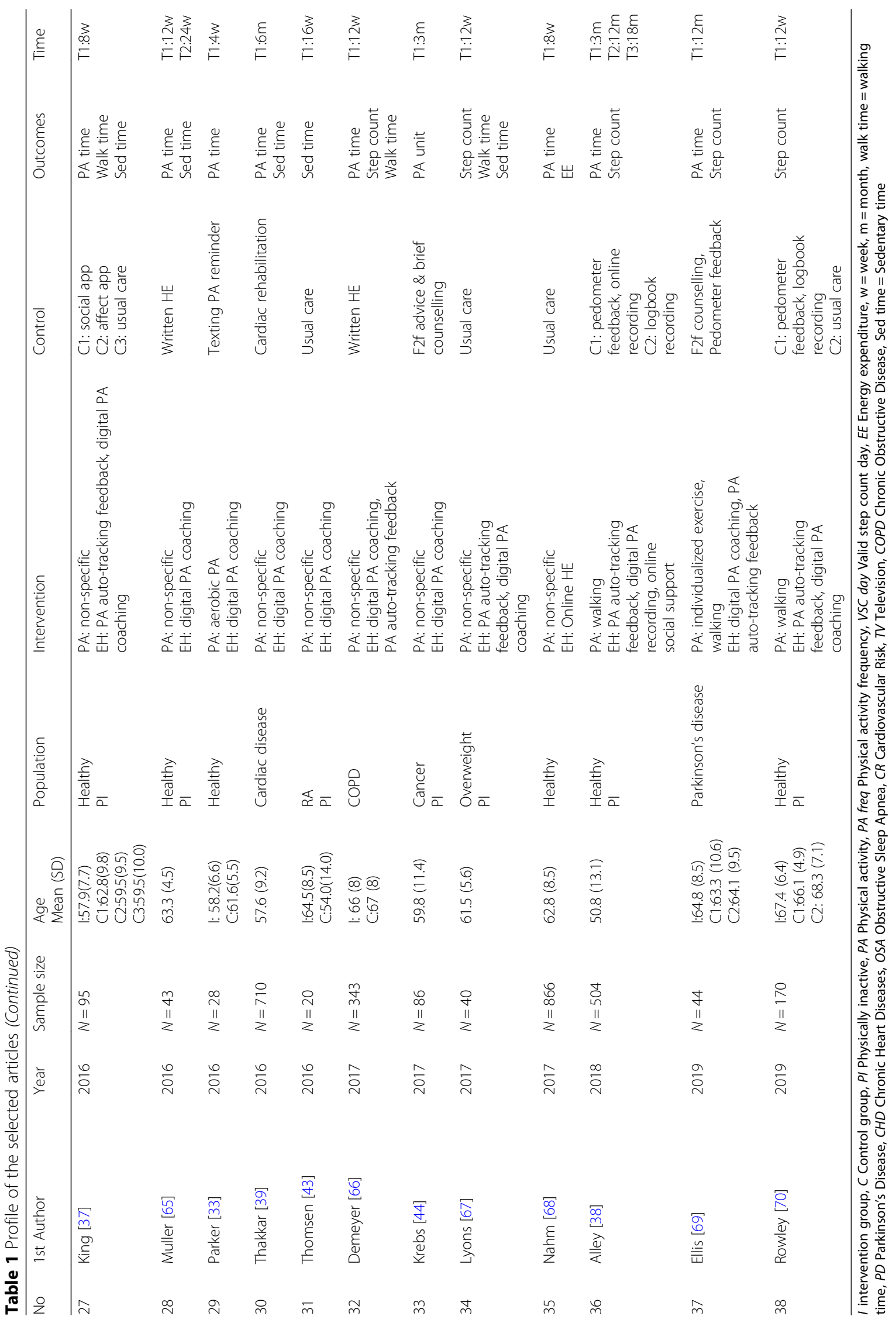


Most of the interventions did not promote a specific type of physical activity $(n=25,65.8 \%)$. Walking was the most common target for the subjects to practise to increase their level of physical activity $(n=7,18.4 \%)$. Other forms of physical activity promoted in the interventions included endurance exercises, stretching, flexibility, and balance, mobilization, resistance, and individualized exercise training.

With regard to the controlled conditions, many studies employed more than one control group, while the usual care was the most commonly used form of control $(n=$ $23,60.5 \%)$. Other studies used active control strategies, such as using fewer e-health strategies, different types of e-health strategies (e.g., social support apps), or nondigital behavioural change strategies (e.g., face-to-face counselling, face-to-face health education, recording steps on logbooks).

Most of the studies employed physical activity time $(n=22,57.9 \%)$ to quantify amounts of physical activity. Other methods were also used to measure physical activity, including step count $(n=13,34.2 \%)$, energy expenditure $(n=10,26.3 \%)$, walking time $(n=7,18.4 \%)$, sedentary time $(n=5,13.2 \%)$, physical activity units calculated by a specific physical activity measuring instruments $(n=6,15.8 \%)$, and physical activity frequency $(n=1,2.6 \%)$.

Most of the studies did not conduct follow-up measurements after T1 $(n=23,60.5 \%)$. The T1 observation time points were from 1 week to 12 months away from the baseline. The post-T follow-up time points were from 2 weeks to 24 months away from the baseline.
Different e-health strategies were identified in the interventions. As shown in Table 2, 11 e-health strategies were used in the identified studies: 1 ) automated advice $(n=2), 2)$ tele-counselling $(n=6), 3)$ digital-tailored advice $(n=7), 4)$ digital physical activity recording $(n=2)$, $5)$ digital physical activity coaching $(n=18), 6)$ online resources $(n=2), 7)$ online social support $(n=1), 8)$ physical activity auto-tracking feedback $(n=15)$, 9) video demonstrations $(n=3), 10)$ video games $(n=1)$, and 11$)$ video vignettes $(n=1)$. Many studies employed multiple e-health strategies concurrently to develop their interventions. The categories are not mutually exclusive. For example, in some studies digital physical activity coaching also included online social support and digital-tailored advice. Earlier studies tended to use fewer e-health strategies, while later studies tended to use more.

Digital physical activity coaching was the most widely adopted method ( $n=18,47.3 \%)$. Multiple behavioural change techniques were employed in the digital physical activity coaching reported in the studies, including setting goals, giving out rewards, making demonstrations, and extending social support. These techniques were implemented on various digital platforms such as text messaging platforms, websites, DVDs, PDAs, and email. Physical activity auto-tracking feedback was the second most adopted method as reported in the identified articles $(n=15,39.5 \%)$. The strategy involves instructing the subjects to wear accelerometer- or pedometer-embedded wearable devices (e.g., smartphones, wrist-worn devices) to track their physical activity levels, and giving feedback to the subjects automatically in terms of graphs or

Table 2 E-health intervention strategies

\begin{tabular}{|c|c|}
\hline E-health strategies & Description \\
\hline 1. Automated advice & $\begin{array}{l}\text { Provide pre-designed physical activity advice (e.g., benefits of physical activities) to participants automatically by } \\
\text { computer or internet. }\end{array}$ \\
\hline 2. Tele-counselling & $\begin{array}{l}\text { Provide physical activity counselling (e.g., goal-setting, prompting, planning) by human facilitators via telephone } \\
\text { or smartphone. }\end{array}$ \\
\hline 3. Digital-tailored advice & $\begin{array}{l}\text { Provide physical activity advice (e.g., time, types, benefits of physical activity) to participants considering the } \\
\text { participants' individuality (e.g., baseline physical activity) by computer or internet. }\end{array}$ \\
\hline 4. Digital PA recording & $\begin{array}{l}\text { Allow participants to input their physical activity performance (e.g., step count) so that participants can } \\
\text { understand the progress of their performance. }\end{array}$ \\
\hline 5. Digital PA coaching & $\begin{array}{l}\text { Providing coaching (e.g., goal setting, prompting, social support, demonstrations) for participants via digital } \\
\text { platforms (e.g., online forums, texting) according to the individuality of the participants (e.g., baseline physical } \\
\text { activity performance, on-going progress). }\end{array}$ \\
\hline 6. Online resources & $\begin{array}{l}\text { Provide physically active lifestyle resources online (e.g., types of physical activity, health benefits of physical } \\
\text { activities, places to perform physical activity). }\end{array}$ \\
\hline 7. Online social support & $\begin{array}{l}\text { Provide an online platform for participants and the facilitator to share their physical activity tips and supportive } \\
\text { messages. }\end{array}$ \\
\hline 8. PA auto-tracking feedback & $\begin{array}{l}\text { Provide automatic tracking and feedback (e.g., trend of step counts, physical activity time, percentage of target } \\
\text { achieved) by wearable devices (e.g., smartphones, wrist bands). }\end{array}$ \\
\hline 9. Video demonstrations & Provide physical activity demonstrations via video (e.g., DVD, online video streaming). \\
\hline 10. Video games & Provide video-game-based activities to enhance physical activity time. \\
\hline 11. Video vignettes & Provide successful stories of behavioural change from being sedentary to becoming physically active. \\
\hline
\end{tabular}


figures that are meaningful to the subjects (e.g., step counts, percentage of physical activity goals achieved).

\section{Risk of bias within studies}

As shown in Table 3, the PEDro total scores of the 38 articles ranged from 2 to 8 . Twenty articles (52.6\%) were rated as good, sixteen $(42.1 \%)$ as fair, and two $(5.3 \%)$ as poor in quality.

\section{Objective 1: identify the within-group effect of the interventions on physical activity}

As shown in Table 4, the within-group effect size (Hedges G) of physical activity time in the intervention group at T1 ranged from 0.12 to 0.84 , step counts from -0.01 to 11.19 , energy expenditure from -0.05 to 0.86 , walking time from 0.13 to 3.33 , sedentary time from 0.12 to -0.28 , physical activity units from -0.41 to 1.86 , and physical activity frequency at 0.84 . The delayed effects as observed in T2 and T3 on physical activity time ranged from 0.24 to 1.24 , and on energy expenditure from 0.15 to 1.32 .

\section{Objective 2: identify the between-group effect of the interventions on physical activity}

In the Forest plot shown in Fig. 2, the between-group effect of the e-health intervention on physical activity time measured by questionnaires was analysed by metaanalysis on nine studies that included 2357 subjects. The result showed minimal heterogeneity among the included studies $\left(\mathrm{I}^{2}=25 \%\right)$. The overall effect showed that the interventions led to a significant increase in physical activity time (mean difference $=53.2 \mathrm{~min} /$ week, $95 \% \mathrm{CI}=$ 30.18-76.21) when compared with the result for the control groups.

In the Forest plot shown in Fig. 3, the between-group effect of the e-health intervention on physical activity time measured using objective wearable devices (i.e., accelerometers) was analysed by meta-analysis on five studies that included 851 subjects. The result showed negligible heterogeneity among the included studies $\left(\mathrm{I}^{2}=0 \%\right)$. The overall effect showed that the interventions led to a significant increase in physical activity time ( mean difference $=12.95 \mathrm{~min} /$ day, $95 \% \mathrm{CI}=10.09-15.82$ ) when compared with the result for the control groups.

In the Forest plot shown in Fig. 4, the between-group effect of the e-health intervention on energy expenditure was analysed by meta-analysis on four studies that included 2123 subjects. The result showed negligible heterogeneity among the four included studies $\left(\mathrm{I}^{2}=0 \%\right)$. The overall effect showed that the interventions led to a significant increase in energy expenditure (mean difference $=194.95 \mathrm{kcal} /$ week,$\quad 95 \% \mathrm{CI}=87.85-302.04)$ when compared with the result for the control groups.
In the Forest plot shown in Fig. 5, the between-group effect of the e-health intervention on step counts measured by objective wearable devices (i.e., accelerometers or pedometers) was analysed by meta-analysis on 11 studies that included 866 subjects. The result showed minimal heterogeneity among the nine included studies $\left(\mathrm{I}^{2}=12 \%\right)$. The overall effect showed that the interventions led to a significant increase in step counts (mean difference $=790$ step $/$ day, $95 \% \mathrm{CI}=300-1280$ ) when compared with the result for the control groups.

For the walking time, the between-group effect of the e-health intervention measured by objective wearable devices (i.e., accelerometers or pedometers) was analysed by meta-analysis on three studies that included 345 subjects. However, the heterogeneity was too high to generate a reliable result for the pooled effect on this outcome $\left(\mathrm{I}^{2}=74 \%\right)$. The between-group effect of the e-health intervention on walking time measured by questionnaires was also analysed by meta-analysis on three studies that included 397 subjects. The heterogeneity was also too high $\left(\mathrm{I}^{2}=85 \%\right)$.

For the outcomes of sedentary time $(n=2)$, physical activity unit $(n=2)$, and physical activity frequency $(n=$ 1 ), there were fewer than three studies that measured these outcomes with comparable instruments and valid data. Therefore, meta-analyses of between-group effects were not conducted on these outcomes.

\section{Discussion}

This is the largest systematic review of previously conducted randomized controlled trials using e-health interventions to promote physical activity in older people to come to the conclusion, from a quantitative determination of their effects, that such interventions are effective. They are particularly effective at increasing the time and energy that older people spend on performing physical activities as well as walking. This is also the first study to have systematically summarized 11 e-health strategies that were employed in those trials to enhance older people's physical activity. These findings have important implications for both clinicians and researchers.

The pooled within-group effect size of the e-health interventions on physical activity time was mild to moderate $(\mathrm{d}=0.12-0.84)$. The effect size was obviously higher than that of conventional behavioural change interventions promoting physical activity in older people as reported in a systematic review $(\mathrm{d}=0.14)$ [18]. This echoes the argument raised in a previous study that conventional behavioural change interventions that have been found to be effective at changing behaviours in younger people may not be as effective in older people [18]. Yet this review supports the view that e-health strategies may be effective at enhancing the effect of conventional behavioural change techniques. A further study should 


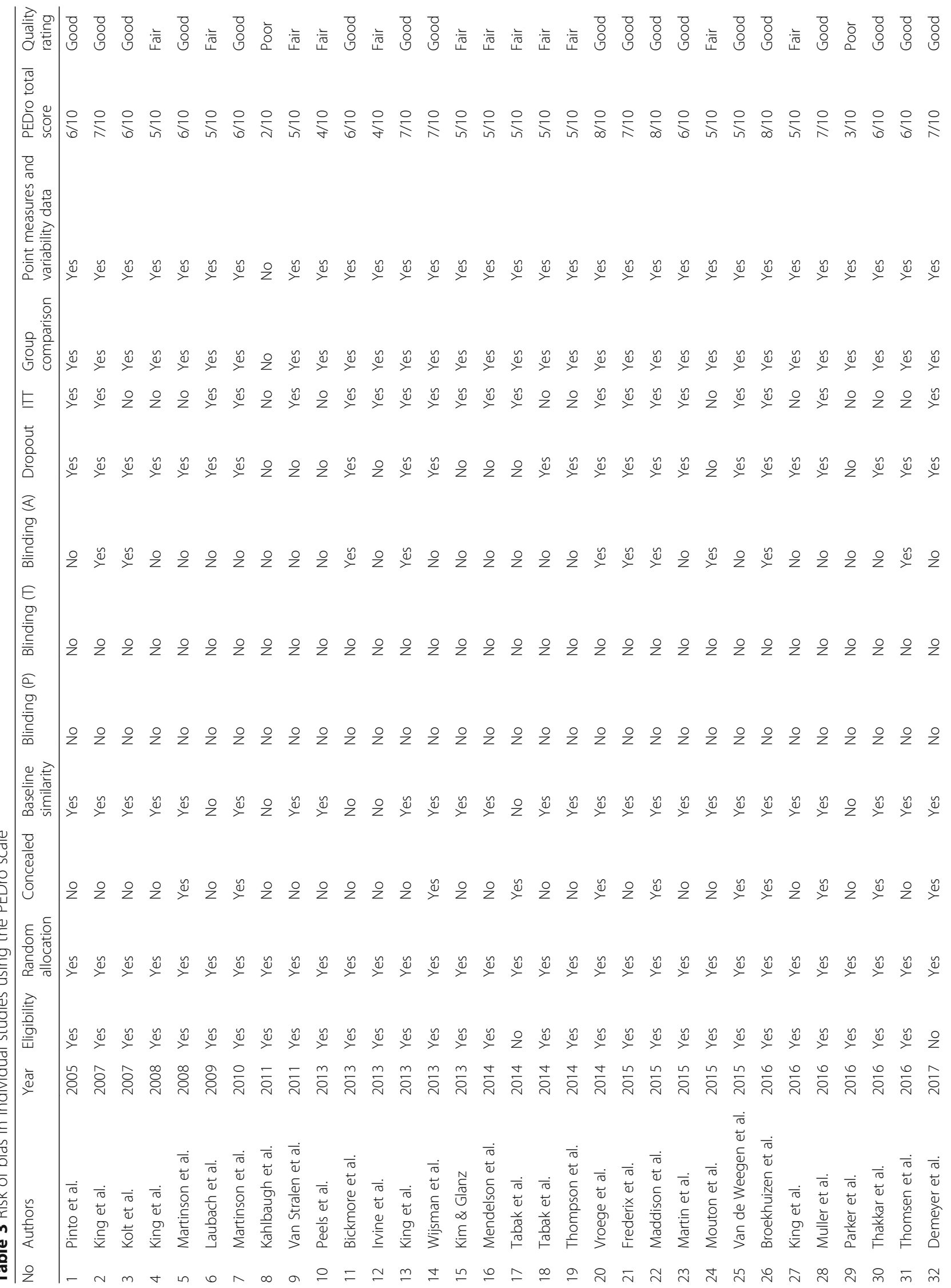




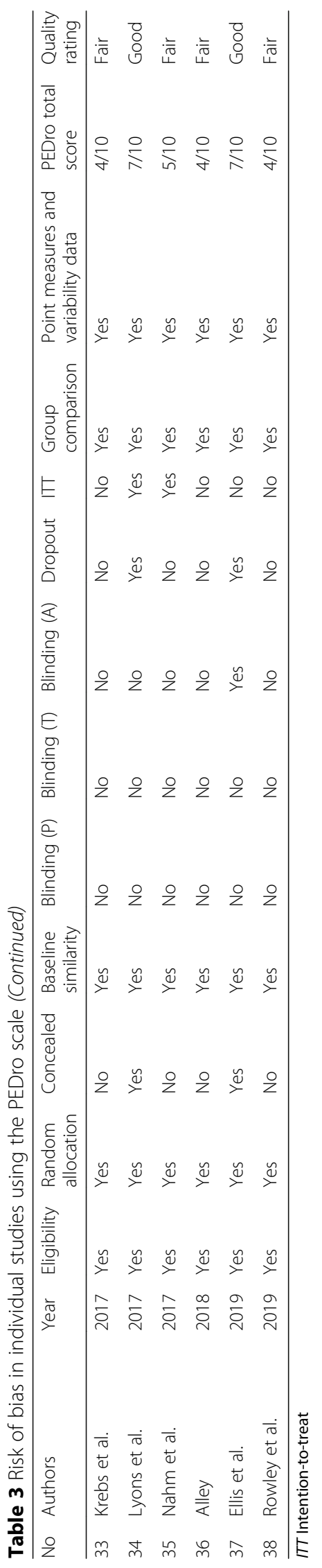


Table 4 Results of individual studies

\begin{tabular}{|c|c|c|c|c|c|c|}
\hline \multirow[t]{2}{*}{ No. } & \multirow[t]{2}{*}{ Author/Year } & \multirow[t]{2}{*}{ Outcome } & \multirow[t]{2}{*}{ Measurement } & \multicolumn{3}{|c|}{ Effect Size - within group (Hedges G) } \\
\hline & & & & $\mathrm{T} 1$ & $\mathrm{~T} 2$ & $\mathrm{~T} 3$ \\
\hline 1 & Pinto 2005 [46] & $\begin{array}{l}\text { PA time } \\
\text { EE } \\
\text { PA unit }\end{array}$ & $\begin{array}{l}\text { 7-Day PAR (min/week) } \\
\text { 7-Day PAR (kcal/day) } \\
\text { Accelerometer (count) }\end{array}$ & $\begin{array}{l}0.58 \\
0.60 \\
0.43\end{array}$ & $\begin{array}{l}0.71 \\
0.72 \\
0.36\end{array}$ & \\
\hline 2 & King 2007 [47] & $\begin{array}{l}\text { EE } \\
\text { PA time } \\
\text { EE } \\
\text { PA time }\end{array}$ & $\begin{array}{l}\text { CHAMPS (kcal/kg/day) } \\
\text { CHAMPS (time/week) } \\
\text { 7-Day PAR (kcal/kg/day) } \\
\text { 7-Day PAR (min/week) }\end{array}$ & $\begin{array}{l}0.86 \\
0.84 \\
0.66 \\
0.79\end{array}$ & $\begin{array}{l}1.32 \\
1.24 \\
0.64 \\
0.62\end{array}$ & \\
\hline 3 & Kolt 2007 [48] & $\begin{array}{l}\text { PA time } \\
\text { Walk time }\end{array}$ & $\begin{array}{l}\text { AHSPAQ (min/week) } \\
\text { AHSPAQ (min/week) }\end{array}$ & $\begin{array}{l}0.18 \\
0.40\end{array}$ & $\begin{array}{l}0.24 \\
0.19\end{array}$ & $\begin{array}{l}0.35 \\
0.21\end{array}$ \\
\hline 4 & King 2008 [49] & $\begin{array}{l}\text { PA time } \\
\text { EE }\end{array}$ & $\begin{array}{l}\text { CHAMPS (min/week) } \\
\text { CHAMPS (kcal/kg/week) }\end{array}$ & $\begin{array}{l}0.77 \\
0.69\end{array}$ & & \\
\hline 5 & Martinson 2008 [45] & $\mathrm{EE}$ & CHAMPS (kcal/week) & -0.03 & & \\
\hline 6 & Laubach 2009 [50] & Step count & Pedometer (step/day) & 0.50 & & \\
\hline 7 & Martinson 2010 [51] & $\mathrm{EE}$ & CHAMPS (kcal/week) & 0.07 & 0.15 & 0.17 \\
\hline 8 & Kahlbaugh 2011 [34] & PA unit & WPAS (score) & NA & & \\
\hline 9 & Van Stralen 2011 [52] & PA time & SQUASH (min/week) & 0.17 & & \\
\hline 10 & Peels 2013 [35] & PA time & SQUASH (min/week) & NA & & \\
\hline 11 & Bickmore 2013 [53] & Step count & Pedometer (step/day) & 0.01 & & \\
\hline 12 & Irvine 2013 [54] & $\begin{array}{l}\text { PA time } \\
\text { PA frequency }\end{array}$ & $\begin{array}{l}\text { SDQ (min/week) } \\
\text { SDQ (count/week) }\end{array}$ & $\begin{array}{l}\text { NA } \\
0.84\end{array}$ & $\begin{array}{l}\text { NA } \\
0.79\end{array}$ & \\
\hline 13 & King 2013 [55] & $\begin{array}{l}\text { Step count } \\
\text { Walk time }\end{array}$ & $\begin{array}{l}\text { Pedometer (step/day) } \\
\text { CHAMPS (min/week) }\end{array}$ & $\begin{array}{l}\text { NA } \\
3.44\end{array}$ & & \\
\hline 14 & Wijsman 2013 [36] & PA time & Accelerometer (min/day) & NA & & \\
\hline 15 & Kim 2013 [56] & $\begin{array}{l}\text { Step count } \\
\text { PA unit }\end{array}$ & $\begin{array}{l}\text { Pedometer (step/day) } \\
\text { LTEQ (score) }\end{array}$ & $\begin{array}{l}0.29 \\
1.86\end{array}$ & & \\
\hline 16 & Mendelson 2014 [57] & $\begin{array}{l}\text { Steps count } \\
\mathrm{EE}\end{array}$ & $\begin{array}{l}\text { Accelerometer (step/day) } \\
\text { Accelerometer (kcal/week) }\end{array}$ & $\begin{array}{l}-0.06 \\
-0.05\end{array}$ & & \\
\hline 17 & Tabak 2014 [58] & $\begin{array}{l}\text { PA unit } \\
\text { PA unit }\end{array}$ & $\begin{array}{l}\text { BPAQ (score) } \\
\text { Accelerometer (count/min) }\end{array}$ & $\begin{array}{l}-0.41 \\
0.13\end{array}$ & $\begin{array}{l}0.07 \\
-0.16\end{array}$ & \\
\hline 18 & Tabak 2014 [59] & Step count & Accelerometer (step/day) & 0.09 & 0,14 & -0.05 \\
\hline 19 & Thompson 2014 [42] & PA unit & Accelerometer (unit/day) & -0.14 & & \\
\hline 20 & Vroege 2014 [60] & PA time & Accelerometer (min/day) & 0.60 & & \\
\hline 21 & Frederix 2015 [41] & $\begin{array}{l}\text { PA time } \\
\text { Step count }\end{array}$ & $\begin{array}{l}\text { IPAQ (min/week) } \\
\text { Accelerometer (step/day) }\end{array}$ & $\begin{array}{l}\text { NA } \\
11.19^{a}\end{array}$ & $\begin{array}{l}N A \\
27.6^{a}\end{array}$ & \\
\hline 22 & Maddison 2015 [61] & $\begin{array}{l}\text { PA time } \\
\text { Walk time }\end{array}$ & $\begin{array}{l}\text { IPAQ (min/week) } \\
\text { IPAQ (min/week) }\end{array}$ & $\begin{array}{l}0.17 \\
0.13\end{array}$ & & \\
\hline 23 & Martin 2015 [62] & $\begin{array}{l}\text { Step count } \\
\text { PA time }\end{array}$ & $\begin{array}{l}\text { Accelerometer (steps/day) } \\
\text { Accelerometer (min/day) }\end{array}$ & $\begin{array}{l}0.39 \\
0.71\end{array}$ & & \\
\hline 24 & Mouton 2015 [71] & PA time & IPAQ (min/week) & 0.33 & & \\
\hline 25 & Van de Weegen 2015 [63] & PA time & Accelerometer (min/day) & 0.75 & 0.76 & \\
\hline 26 & Broekhuizen 2016 [64] & PA time & Accelerometer (min/day) & 0.59 & & \\
\hline 27 & King 2016 [37] & $\begin{array}{l}\text { PA time } \\
\text { Sed time } \\
\text { Walk time }\end{array}$ & $\begin{array}{l}\text { Accelerometer (min/day) } \\
\text { Accelerometer (min/day) } \\
\text { Accelerometer (min/day) }\end{array}$ & & & \\
\hline 28 & Muller 2016 [65] & $\begin{array}{l}\text { PA time } \\
\text { Sed time }\end{array}$ & $\begin{array}{l}\text { IPAQ-S (min/week) } \\
\text { IPAQ-S (hr/day) }\end{array}$ & $\begin{array}{l}0.75 \\
-0.12\end{array}$ & $\begin{array}{l}0.85 \\
-0.03\end{array}$ & \\
\hline 29 & Parker 2016 [33] & PA time & EPAP (min/week) & NA & & \\
\hline 30 & Thakkar 2016 [39] & $\begin{array}{l}\text { PA time } \\
\text { Sed time }\end{array}$ & $\begin{array}{l}\mathrm{GPAQ}(\mathrm{min} / \text { week }) \\
\mathrm{GPAQ}(\mathrm{min} / \text { week })\end{array}$ & $\begin{array}{l}0.82 \\
\text { NA }\end{array}$ & & \\
\hline 31 & Thomsen 2016 [43] & Sed time & ActivPAL3 (hours/day) & -0.15 & & \\
\hline
\end{tabular}


Table 4 Results of individual studies (Continued)

\begin{tabular}{lllll}
\hline No. & Author/Year & Outcome & Measurement & Effect Size - within group (Hedges G) \\
\cline { 3 - 4 } & & & T1 \\
\hline 32 & Demeyer 2017 [66] & Step count & Accelerometer (step/day) & 0.11 \\
& & PA time & Accelerometer (min/day) & 0.12 \\
33 & Walk time & Accelerometer (min/day) & 0.19 \\
34 & Krebs 2017 [44] & PA unit & GLTEQ (MET units/week) & -0.16 \\
& Lyons 2017 [67] & Step count & Accelerometer (step/day) & 0.41 \\
35 & Nahm 2017 [68] & Sed time & Accelerometer (min/day) & 0.58 \\
& & PA time & YPAS (min/week) & -0.28 \\
36 & Alley 2018 [38] & EE & YPAS (kcal/week) & 0.21 \\
& & PA time & Accelerometer (min/day) & 0.21 \\
37 & Ellis 2019 [69] & Step count & Accelerometer (step/day) & $\mathrm{NA}$ \\
& & Steps count & Pedometer (step/day) & 0.01 \\
38 & Rowley 2019 [40] & PA time & Pedometer (min/day) & 0.13 \\
\hline
\end{tabular}

a Outlining effect size, which was excluded from the meta-analysis

PA Physical activity, EE Energy expenditure, Sed time Sedentary time, CHAMPS Community Healthy Activities Model Program questionnaire for older adults, SQUASH Short questionnaire to assess health enhancing physical activity, GLTEQ Godin Leisure Time Exercise Questionnaire, YPAS Yale Physical Activity Survey, EPAP Electronic Physical Activity Participation Form, WPAS Weekly Physical Activity Scale, 7-Day = 7-Day Physical Activity Recall, AHSPAQ Auckland Heart Study Physical Activity Questionnaire, BPAQ Baecke Physical Activity Questionnaire, GPAQ Global Physical Activity Questionnaire; GPPAQ General Practice Physical Activity Questionnaire, SDQ Self-developed questionnaire

be conducted to test which e-health strategies are more effective at promoting physical activity in older people.

The pooled between-group effect size of the e-health interventions promoting physical activity is seemingly clinically meaningful in authors' opinion. It is because the participants in the intervention groups had a mean difference of 53.2 more physical activity minutes per week as measured by actigraphs and 90.7 more physical activity minutes per week as measured by questionnaires than those in the control groups. These differences are over 35 and $60 \%$ of the physical activity time recommended by WHO as yielding health benefits in older people (i.e., $150 \mathrm{~min} /$ week) [8]. Therefore, it is recommended that e-health interventions be included in guidelines for promoting physical activity in older people.

In the subgroup analysis, the effect of e-health interventions on the physical activity time between that measured by actigraphs and that measured by questionnaires was observed to be quite different. The physical activity measured by questionnaires was observed to have a much higher value than that measured by actigraphs. This observation is comparable with what was reported in the literature, namely, that the use of questionnaires likely leads to over-estimations of actual physical activity [72]. In order to more precisely identify the effects of ehealth interventions, future studies should adopt objective measurements of physical activity.

Earlier studies showed that the common reasons for older people to avoid performing physical activities are inconvenience and a lack of access to physical activity programmes [68]. This review found that walking is the most commonly targeted physical activity for older people since there are no problems involved with gaining access to programmes, because it is an activity that can be practised anywhere. This review also showed that participants in the e-health intervention groups walked significantly more than those in the control groups (mean difference $=790$ steps/day). Walking at a speed of $2.5 \mathrm{~km} / \mathrm{hr}$. is sufficient for older people to achieve the intensity of MVPA [73]. Therefore, it is advocated that

\begin{tabular}{|c|c|c|c|c|c|c|c|c|c|c|c|c|}
\hline Study or Subgroup & \multicolumn{3}{|c|}{ Experimental } & \multicolumn{3}{|c|}{ Control } & \multicolumn{3}{|c|}{ Mean Difference } & \multicolumn{3}{|c|}{$\begin{array}{c}\text { Mean Difference } \\
\text { IV, Random, } 95 \% \mathrm{Cl}[\mathrm{min} / \mathrm{wk}]\end{array}$} \\
\hline Pinto 2005 & 89.4 & 105.2 & 52 & 50.6 & 83 & 48 & $21.7 \%$ & $38.80[1.80,75.80]$ & 2005 & & & $=$ \\
\hline Kolt 2007 & 138.9 & 171.9 & 93 & 86.7 & 122.5 & 93 & $18.2 \%$ & $52.20[9.30,95.10]$ & 2007 & & & - \\
\hline King 2007 & 185.4 & 154.1 & 61 & 111.3 & 154.5 & 62 & $13.1 \%$ & $74.10[19.56,128.64]$ & 2007 & & & - \\
\hline King 2008 & 301.6 & 298.3 & 19 & 135 & 208.2 & 18 & $1.9 \%$ & $166.60[1.55,331.65]$ & 2008 & & & \\
\hline Van Stralen 2011 & 703 & 443 & 455 & 619 & 448 & 465 & $12.1 \%$ & $84.00[26.42,141.58]$ & 2011 & & & $\rightarrow$ \\
\hline Mouton 2015 & $1,578.4$ & 710 & 38 & $1,373.9$ & 863.3 & 38 & $0.4 \%$ & $204.50[-150.89,559.89]$ & 2015 & & & \\
\hline Maddison 2015 & 383.2 & 377 & 85 & 273 & 277 & 86 & $4.8 \%$ & $110.20[10.95,209.45]$ & 2015 & & & - \\
\hline Muller 2016 & $1,045.3$ & 497.3 & 18 & $1,346.1$ & $1,479.1$ & 21 & $0.1 \%$ & $-300.80[-973.83,372.23]$ & 2016 & & & \\
\hline Nahm 2017 & 149.1 & 200 & 460 & 125.6 & 177.9 & 245 & $27.8 \%$ & $23.50[-5.31,52.31]$ & 2017 & & & $=$ \\
\hline Total $(95 \% \mathrm{Cl})$ & & & 1281 & & & 1076 & $100.0 \%$ & $53.20[30.18,76.21]$ & & & & 1 \\
\hline $\begin{array}{l}\text { Heterogeneity: } \mathrm{Tau}^{2}= \\
\text { Test for overall effect: }\end{array}$ & $\begin{array}{l}280.11 ; \mathrm{Chi}^{2}=10.6 \\
Z=4.53(P<0.000\end{array}$ & $\begin{array}{l}69, \mathrm{df}=8(\mathrm{P}= \\
\text { 001) }\end{array}$ & $0.22) ; 1^{2}$ & $\left.\right|^{2}=25 \%$ & & & & & & -1000 & \begin{tabular}{c|}
1 \\
-500 \\
Favours [control]
\end{tabular} & $\begin{array}{lcc} & 1 \\
0 & 500 & 1000 \\
\text { Favours [experimentall] }\end{array}$ \\
\hline
\end{tabular}




\begin{tabular}{|c|c|c|c|c|c|c|c|c|c|c|}
\hline Study or Subgroup & \multicolumn{3}{|c|}{ Experimental } & \multicolumn{3}{|c|}{ Control } & \multicolumn{2}{|r|}{ Mean Difference } & \multicolumn{2}{|c|}{$\begin{array}{c}\text { Mean Difference } \\
\text { IV, Random, } 95 \% \mathrm{CI}[\mathrm{min} / \text { day] }\end{array}$} \\
\hline Vroege 2014 & 27.9 & 18.6 & 114 & 14.4 & 24.3 & 112 & $25.7 \%$ & $13.50[7.85,19.15] 2014$ & & $=$ \\
\hline Martin 2015 & 26 & 18 & 16 & 10 & 18 & 16 & $5.3 \%$ & $16.00[3.53,28.47] 2015$ & & \\
\hline Van der Weegen 2015 & 48.2 & 23.8 & 65 & 39.6 & 19.5 & 68 & $14.9 \%$ & $8.60[1.19,16.01] 2015$ & & \\
\hline Broekhuizen 2016 & 27.9 & 18.6 & 114 & 14.3 & 23.8 & 116 & $27.0 \%$ & $13.60[8.08,19.12] 2016$ & & —- \\
\hline Demeyer 2017 & 27.9 & 18.6 & 114 & 14.3 & 23.8 & 116 & $27.0 \%$ & $13.60[8.08,19.12] 2017$ & & $\overline{5}$ \\
\hline Total $(95 \% \mathrm{Cl})$ & & & 423 & & & 428 & $100.0 \%$ & $12.95[10.09,15.82]$ & & \\
\hline \multicolumn{4}{|c|}{$\begin{array}{l}\text { Heterogeneity: } \mathrm{Tau}^{2}=0.00 ; \mathrm{Chi}^{2}=1.70, \mathrm{df}=4(\mathrm{P}=0.79) ; \mathrm{I}^{2}=0 \% \\
\text { Test for overall effect: } Z=8.86(P<0.00001)\end{array}$} & & & & & & $\begin{array}{cc}-20 & -10 \\
\text { Favours [control] }\end{array}$ & $\begin{array}{lcr}0 & 10 & 2 \\
11] & \text { Favours [experim }\end{array}$ \\
\hline
\end{tabular}

Fig. 3 Florest plot of the effect of e-health interventions on physical activity time measured by objective wearable devices

walking be the physical activity that is targeted for promotion in older people.

Lack of social support and fear of falling were also identified in the literature as common barriers to the participation of physical activity by older people [74]. This review found that online social support is a common e-health strategy to promote physical activity in older people. Studies echoed the view that online social support is effective at increasing physical activity in
There are several limitations in this review. Most of the control groups in the included studies employed the usual care, but some of them employed an active control. The meta-analysis may have underestimated the effect of this practice. A few randomized controlled trials did not employ parallel groups, leading to uneven group sizes between intervention groups and control groups. This review included a small portion of subjects who are under 60 years old because some trials aimed to recruit

\begin{tabular}{|c|c|c|c|c|c|c|c|c|c|c|c|c|}
\hline \multirow[b]{2}{*}{ Study or Subgroup } & \multicolumn{3}{|c|}{ Experimental } & \multicolumn{3}{|c|}{ Control } & \multicolumn{3}{|c|}{ Mean Difference } & \multirow{2}{*}{\multicolumn{3}{|c|}{$\begin{array}{c}\text { Mean Difference } \\
\text { IV, Random, } 95 \% \mathrm{Cl}[\mathrm{kcal} / \mathrm{wk}]\end{array}$}} \\
\hline & Mean $[\mathrm{kcal} / \mathrm{wk}]$ & $\mathrm{SD}[\mathrm{kcal} / \mathrm{wk}]$ & Total & Mean [kcal/wk] & $\mathrm{SD}[\mathrm{kcal} / \mathrm{wk}]$ & Total & Weight & IV, Random, $95 \% \mathrm{Cl}[\mathrm{kcal} / \mathrm{wk}]$ & Year & & & \\
\hline Pinto 2005 & 6 & 7 & 52 & 3.4 & 5.6 & 48 & $0.0 \%$ & $2.60[0.12,5.08]$ & 2005 & & & \\
\hline King 2007 & 1,134 & 630 & 61 & 910 & 682 & 62 & $21.3 \%$ & $224.00[-7.98,455.98]$ & 2007 & & & \\
\hline King 2008 & $1,176.5$ & 1,248 & 19 & 578.5 & 864.5 & 18 & $2.4 \%$ & $598.00[-90.76,1286.76]$ & 2008 & & & $\longrightarrow$ \\
\hline Martinson 2010 & 2,008 & $1,646.6$ & 523 & 1,764 & 1,704 & 490 & $26.9 \%$ & $244.00[37.41,450.59]$ & 2010 & & & $\longrightarrow-$ \\
\hline Nahm 2017 & 824.6 & $1,130.2$ & 705 & 688.6 & $1,018.3$ & 245 & $49.4 \%$ & $136.00[-16.38,288.38]$ & 2017 & & & -6 \\
\hline Total $(95 \% \mathrm{Cl})$ & & & 1308 & & & 815 & $100.0 \%$ & $194.95[87.85,302.04]$ & & & & \\
\hline $\begin{array}{l}\text { Heterogeneity: } \mathrm{Tau}^{2}= \\
\text { Test for overall effect: }\end{array}$ & $\begin{array}{l}0.00 ; \mathrm{Chi}^{2}=2.17 \\
Z=3.57(P=0.00\end{array}$ & $\begin{array}{l}\mathrm{df}=3(P=0.54 \\
04)\end{array}$ & $4) ; 1^{2}=0$ & & & & & & & -1000 & $\begin{array}{c}-500 \quad 0 \\
\text { Favours [control] }\end{array}$ & \begin{tabular}{|ccc}
0 & 500 & 1000 \\
Favours [experimental]
\end{tabular} \\
\hline
\end{tabular}

young adults [75]. This review also found that automatic tracking by wearable devices is another common strategy to promote physical activity in older people. Falling and being at risk of falling can in fact be feasibly and accurately detected by wearable devices (e.g., accelerometers and gyroscopes) [76]. Early studies had already shown that fall detectors reduce a person's fear of falling [77]. Therefore, these strategies should also be embraced in future e-health interventions specifically designed to promote physical activity in older people. older people but they did not specifically exclude people younger than 60 years. More eligible articles may possibly be unincluded if they were not identified by our search strategies.

\section{Conclusion}

E-health interventions are effective at increasing the amount of time spent on physical activity, the energy expended in physical activity, and the number of walking steps. It is recommended that e-health interventions be

\begin{tabular}{|c|c|c|c|c|c|c|c|c|c|c|}
\hline \multirow{2}{*}{ Study or Subgroup } & \multicolumn{3}{|c|}{ Experimental } & \multicolumn{3}{|c|}{ Control } & \multicolumn{2}{|r|}{ Mean Difference } & \multirow{2}{*}{\multicolumn{2}{|c|}{$\begin{array}{c}\text { Mean Difference } \\
\text { IV, Random, } 95 \% \text { Cl [1000step/d] }\end{array}$}} \\
\hline & 9.372 & 2.799 & 20 & 9147 & 2107 & 10 & $69 \%$ & IV, Random, 95\% Cl [1000step/d] Year & & \\
\hline & & & & & & & & $0.22[-1.57,2.02] 2009$ & & \\
\hline & 4.365 & $2.95 \%$ & 132 & 4.033 & 2.573 & 131 & $34.1 \%$ & $0.33[-0.34,1.00] 2013$ & & $t-$ \\
\hline Kim 2013 & 6.531 & 2.648 & 26 & 4.78 & 1.978 & 15 & $10.5 \%$ & $1.75[0.32,3.18] 2013$ & & $\longrightarrow$ \\
\hline Mendelson 2014 & 7.743 & 4.344 & 54 & 6.35 & 2.993 & 53 & $10.7 \%$ & $1.39[-0.02,2.80] 2014$ & & \\
\hline Tabak-b 2014 & 6.106 & 3.479 & 13 & 4.853 & 3.46 & 16 & $3.6 \%$ & $1.25[-1.29,3.79] 2014$ & & \\
\hline Martin 2015 & 11.384 & 4.35 & 16 & 8.628 & 4.35 & 16 & $2.6 \%$ & $2.76[-0.26,5.77] 2015$ & & \\
\hline Frederix 2015 & 7.799 & 0.037 & 70 & 6.63 & 0.011 & 70 & $0.0 \%$ & $1.17[1.16,1.18] 2015$ & & \\
\hline Demeyer 2017 & 4.767 & 4.869 & 140 & 4.059 & 3.708 & 140 & $18.7 \%$ & $0.71[-0.31,1.72] 2017$ & & - - \\
\hline Lyons 2017 & 6.193 & 3.183 & 20 & 4.586 & 2.476 & 20 & $7.1 \%$ & $1.61[-0.16,3.37] 2017$ & & \\
\hline Ellis 2019 & 8.457 & 3.184 & 23 & 9.028 & 3.366 & 21 & $6.0 \%$ & $-0.57[-2.51,1.37] 2019$ & & - \\
\hline Rowley 2019 & 10.286 & 3.022 & 57 & 4.456 & 1.447 & 51 & $0.0 \%$ & $5.83[4.95,6.71] 2019$ & & \\
\hline Total $(95 \% \mathrm{Cl})$ & & & 444 & & & 422 & $100.0 \%$ & $0.79[0.30,1.28]$ & & \\
\hline $\begin{array}{l}\text { Heterogeneity: } \mathrm{Tau}^{2}= \\
\text { Test for overall effect: }\end{array}$ & $\begin{array}{l}0.07 ; \mathrm{Chi}^{2}=9.05, \mathrm{df}= \\
Z=3.16(P=0.002)\end{array}$ & $8(P=0.34) ; I^{2}=1$ & & & & & & & $\begin{array}{ccc}1 & 1 & 1 \\
-4 & -2 & 0 \\
\text { Favours [control] }\end{array}$ & $\begin{array}{ccc} & 1 & 1 \\
0 & 2 & 4 \\
\text { Favours [experimental] }\end{array}$ \\
\hline
\end{tabular}


included in guidelines to enhance physical activity in older people. Walking is the most common form of targeted physical activity promoted in e-health interventions. It is recommended that online social support and automatic tracking (e.g., fall detection and physical activity monitoring) be included in future e-health interventions in order to enhance the effect of those interventions. Further studies should be conducted to examine which e-health strategies are more effective.

\section{Abbreviations}

MVPA: Moderate-to-vigorous physical activity; DVD: Digital versatile disc; PDA: Personal digital assistant; Cl: Confidence interval; WHO: World Health Organization

\section{Acknowledgments}

The authors would like to thank Ms. Deborah Lee for supporting the data cleaning and extraction for this review.

\section{Authors' contributions}

RK developed the research questions under the lead of KC. RK and DS conducted the literature search. DC, MT, RK did the screening and made decision on the eligibility of articles. RK, DS, IR conducted the data extraction, verifying data correctness, and prepared the tables. PL conducted and supervised the statistical analysis. RK, DS, IR drafted the manuscript and $\mathrm{PL}, \mathrm{MT}, \mathrm{DC}, \mathrm{KC}$ critically commented and revised the manuscript. The author(s) read and approved the final manuscript.

\section{Funding}

Nil

\section{Availability of data and materials}

The datasets during and/or analysed during the current study available from the corresponding author on reasonable request.

\section{Ethics approval and consent to participate}

Not applicable (because this is a review article).

\section{Consent for publication}

Not applicable (because this review article contains no data from individuals).

\section{Competing interests}

The authors declare that they have no competing interests.

\section{Author details}

${ }^{1}$ Centre for Gerontological Nursing, School of Nursing, The Hong Kong Polytechnic University, GH502, 5/F, Block G, Hung Hom, Kowloon, Hong Kong, China. ${ }^{2}$ School of Nursing, The Hong Kong Polytechnic University, Hong Kong, China. ${ }^{3}$ Ramathibodi School of Nursing, Faculty of Medicine Ramathibodi Hospital, Mahidol University, Bangkok, Thailand.

Received: 29 January 2020 Accepted: 30 March 2020

Published online: 21 April 2020

\section{References}

1. Caspersen CJ, Powell KE, Christenson GM. Physical activity, exercise, and physical fitness: definitions and distinctions for health-related research. Public Health Rep (Washington, DC : 1974). 1985;100(2):126-31.

2. Gregg EW, Cauley JA, Stone K, Thompson TJ, Bauer DC, Cummings SR, et al. Relationship of changes in physical activity and mortality among older women. JAMA. 2003;289(18):2379-86.

3. Baker LD, Frank LL, Foster-Schubert K, Green PS, Wilkinson CW, McTiernan A, et al. Effects of aerobic exercise on mild cognitive impairment: a controlled TrialTrial of aerobic exercise for mild cognitive impairment. Arch Neurol. 2010;67(1):71-9.

4. Lautenschlager NT, Cox KL, Flicker L, Foster JK, van Bockxmeer FM, Xiao J, et al. Effect of physical activity on cognitive function in older adults at risk for Alzheimer disease: a randomized trial. Jama. 2008;300(9):1027-37.
5. Northey JM, Cherbuin N, Pumpa KL, Smee DJ, Rattray B. Exercise interventions for cognitive function in adults older than 50: a systematic review with meta-analysis. Br J Sports Med. 2018;52(3):154-60.

6. de Labra C, Guimaraes-Pinheiro C, Maseda A, Lorenzo T, Millán-Calenti JC. Effects of physical exercise interventions in frail older adults: a systematic review of randomized controlled trials. BMC Geriatr. 2015;15(1):154.

7. Chou WT, Tomata Y, Watanabe T, Sugawara Y, Kakizaki M, Tsuji I. Relationships between changes in time spent walking since middle age and incident functional disability. Prev Med. 2014;59:68-72.

8. World Health Organization. Global recommendations on physical activity for health, vol. 2016. Geneva: World Health Organization; 2010.

9. Harvey JA, Chastin SF, Skelton DA. Prevalence of sedentary behavior in older adults: a systematic review. Int J Environ Res Public Health. 2013;10(12): 6645-61.

10. Sun F, Norman IJ, While AE. Physical activity in older people: a systematic review. BMC Public Health. 2013;13(1):449.

11. Sparling PB, Howard BJ, Dunstan DW, Owen N. Recommendations for physical activity in older adults. BMJ. 2015;350:h100.

12. Moschny A, Platen P, Klaaßen-Mielke R, Trampisch U, Hinrichs T. Barriers to physical activity in older adults in Germany: a cross-sectional study. Int J Behav Nutr Phys Act. 2011;8(1):121.

13. Dunlop DD, Song J, Arnston EK, Semanik PA, Lee J, Chang RW, et al. Sedentary time in US older adults associated with disability in activities of daily living independent of physical activity. J Phys Act Health. 2015;12(1):93-101.

14. Hupin D, Roche F, Gremeaux V, Chatard J-C, Oriol M, Gaspoz J-M, et al. Even a low-dose of moderate-to-vigorous physical activity reduces mortality by $22 \%$ in adults aged $\geq 60$ years: a systematic review and meta-analysis. $\mathrm{Br}$ J Sports Med. 2015;49(19):1262-7.

15. Bandura A. Human agency in social cognitive theory. Am Psychol. 1989; 44(9):1175-84

16. van Sluijs EMF, McMinn AM, Griffin SJ. Effectiveness of interventions to promote physical activity in children and adolescents: systematic review of controlled trials. BMJ. 2007;335(7622):703.

17. Brown T, Summerbell C. Systematic review of school-based interventions that focus on changing dietary intake and physical activity levels to prevent childhood obesity: an update to the obesity guidance produced by the National Institute for health and clinical excellence. Obes Rev. 2009;10(1): 110-41.

18. Mc Sharry J, French DP, Olander EK, Chisholm A. Which behaviour change techniques are Most effective at increasing older adults' self-efficacy and physical activity behaviour? A systematic review. Ann Behav Med. 2014; 48(2):225-34.

19. Eysenbach G. What is e-health? J Med Internet Res. 2001;3(2):e20.

20. Matthews J, Win KT, Oinas-Kukkonen H, Freeman M. Persuasive technology in mobile applications promoting physical activity: a systematic review. J Med Syst. 2016;40(3):72.

21. Najafi B, Armstrong DG, Mohler J. Novel wearable Technology for Assessing Spontaneous Daily Physical Activity and Risk of falling in older adults with diabetes. J Diabetes Sci Technol. 2013;7(5):1147-60.

22. Direito A, Dale LP, Shields E, Dobson R, Whittaker R, Maddison R. Do physical activity and dietary smartphone applications incorporate evidencebased behaviour change techniques? BMC Public Health. 2014;14(1):646.

23. Lau PW, Lau EY, Wong DP, Ransdell L. A systematic review of information and communication technology-based interventions for promoting physical activity behavior change in children and adolescents. J Med Internet Res. 2011;13(3):e48.

24. Sullivan AN, Lachman ME. Behavior change with fitness technology in sedentary adults: a review of the evidence for increasing physical activity. Front Public Health. 2017:4(289):289.

25. Muellmann S, Forberger S, Möllers T, Bröring E, Zeeb H, Pischke CR. Effectiveness of eHealth interventions for the promotion of physical activity in older adults: a systematic review. Prev Med. 2018;108:93-110.

26. Elavsky S, Knapova L, Klocek A, Smahel D. Mobile health interventions for physical activity, sedentary behavior, and sleep in adults aged 50 years and older: a systematic literature review. J Aging Phys Act. 2019;00:1-29.

27. Moher D, Liberati A, Tetzlaff J, Altman DG. Preferred reporting items for systematic reviews and meta-analyses: the PRISMA statement. Ann Intern Med. 2009:151(4):264-9.

28. Crumley ET, Wiebe N, Cramer K, Klassen TP, Hartling L. Which resources should be used to identify RCT/CCTs for systematic reviews: a systematic review. BMC Med Res Methodol. 2005;5(1):24. 
29. Maher CG, Sherrington C, Herbert RD, Moseley AM, Elkins M. Reliability of the PEDro scale for rating quality of randomized controlled trials. Phys Ther. 2003;83(8):713-21.

30. Higgins JP, Green S. Cochrane handbook for systematic reviews of interventions. West Sussex: Wiley; 2011.

31. Chandler J, Cumpston M, Li T, Page MJ, Welch VA. Cochrane handbook for systematic reviews of interventions. Wiley; 2019.

32. Borenstein M, Hedges LV, Higgins JPT, Rothstein HR. A basic introduction to fixed-effect and random-effects models for meta-analysis. Res Synth Methods. 2010;1(2):97-111.

33. Parker CA, Ellis R. Effect of electronic messaging on physical activity participation among older adults. J Aging Res. 2016;2016:6171028.

34. Kahlbaugh PE, Sperandio AJ, Carlson AL, Hauselt J. Effects of playing Wii on well-being in the elderly: physical activity, loneliness, and mood. Act Adapt Aging. 2011;35(4):331-44.

35. Peels DA, Bolman C, Golsteijn RHJ, de Vries H, Mudde AN, van Stralen MM, et al. Long-term efficacy of a printed or a web-based tailored physical activity intervention among older adults. Int J Behav Nutr Phys Act. 2013; 10(1):104.

36. Wijsman CA, Westendorp RG, Verhagen EA, Catt M, Slagboom PE, de Craen AJ, et al. Effects of a web-based intervention on physical activity and metabolism in older adults: randomized controlled trial. J Med Internet Res. 2013;15(11):e233.

37. King AC, Hekler EB, Grieco LA, Winter SJ, Sheats JL, Buman MP, et al. Effects of three motivationally targeted mobile device applications on initial physical activity and sedentary behavior change in midlife and older adults: a randomized trial. PLoS One. 2016;11(6):e0156370.

38. Alley SJ, Kolt GS, Duncan MJ, Caperchione CM, Savage TN, Maeder AJ, et al. The effectiveness of a web 2.0 physical activity intervention in older adultsa randomised controlled trial. Int J Behav Nutr Phys Act. 2018;15(1):4.

39. Thakkar J, Redfern J, Thiagalingam A, Chow CK. Patterns, predictors and effects of texting intervention on physical activity in CHD-insights from the TEXT ME randomized clinical trial. Eur J Prev Cardiol. 2016;23(17):1894-902.

40. Rowley TW, Lenz EK, Swartz AM, Miller NE, Maeda H, Strath SJ. Efficacy of an individually tailored, internet-mediated physical activity intervention in older adults: a randomized controlled trial. J Appl Gerontol. 2019;38(7):1011-22.

41. Frederix I, Hansen D, Coninx K, Vandervoort P, Vandijck D, Hens N, et al. Medium-term effectiveness of a comprehensive internet-based and patientspecific telerehabilitation program with text messaging support for cardiac patients: randomized controlled trial. J Med Internet Res. 2015;17(7):e185.

42. Thompson WG, Kuhle CL, Koepp GA, McCrady-Spitzer SK, Levine JA. "Go4Life" exercise counseling, accelerometer feedback, and activity levels in older people. Arch Gerontol Geriatr. 2014;58(3):314-9.

43. Thomsen T, Aadahl M, Beyer N, Hetland ML, Løppenthin K, Midtgaard J, et al. Motivational counselling and SMS-reminders for reduction of daily sitting time in patients with rheumatoid arthritis: a descriptive randomised controlled feasibility study. BMC Musculoskelet Disord. 2016;17(1):434.

44. Krebs P, Shtaynberger J, McCabe M, locolano M, Williams K, Shuk E, et al. An eHealth intervention to increase physical activity and healthy eating in older adult cancer survivors: summative evaluation results. JMIR Cancer. 2017;3(1):e4.

45. Martinson BC, Crain AL, Sherwood NE, Hayes M, Pronk NP, O'Connor PJ. Maintaining physical activity among older adults: six-month outcomes of the keep active Minnesota randomized controlled trial. Prev Med. 2008; 46(2):111-9.

46. Pinto BM, Goldstein MG, Ashba J, Sciamanna CN, Jette A. Randomized controlled trial of physical activity counseling for older primary care patients. Am J Prev Med. 2005;29(4):247-55.

47. King AC, Friedman R, Marcus B, et al. Ongoing physical activity advice by humans versus computers: the community health advice by telephone (CHAT) trial. Health Psychol. 2007;26(6):718-27.

48. Kolt GS, Schofield GM, Kerse N, Garrett N, Oliver M. Effect of telephone counseling on physical activity for low-active older people in primary care: a randomized, controlled trial. J Am Geriatr Soc. 2007;55(7):986-92.

49. King AC, Ahn DK, Oliveira BM, et al. Promoting physical activity through hand-held computer technology. Am J Prev Med. 2008;34(2):138-42.

50. Laubach $L$, Porter $K$, Hovey $P$, Linderman JON. A modest increase in weekly step counts improved cardiovascular function in healthy elderly women. J Exerc Physiol Online. 2009;12(6):25-32

51. Martinson BC, Sherwood NE, Crain AL, et al. Maintaining physical activity among older adults: 24-month outcomes of the keep active Minnesota randomized controlled trial. Prev Med. 2010;51(1):37-44.
52. van Stralen MM, de Vries H, Mudde AN, Bolman C, Lechner L. The long-term efficacy of two computer-tailored physical activity interventions for older adults: Main effects and mediators. Health Psychol. 2011;30(4):442-52.

53. Bickmore TW, Silliman RA, Nelson $\mathrm{K}$, et al. A randomized controlled trial of an automated exercise coach for older adults. J Am Geriatr Soc. 2013;61(10): 1676-83.

54. Irvine AB, Gelatt VA, Seeley JR, Macfarlane P, Gau JM. Web-based intervention to promote physical activity by sedentary older adults: randomized controlled trial. J Med Internet Res. 2013;15(2):e19.

55. King AC, Bickmore TW, Campero MI, Pruitt LA, Yin JL. Employing virtual advisors in preventive Care for Underserved Communities: results from the COMPASS study. J Health Commun. 2013;18(12):1449-64.

56. Kim BH, Glanz K. Text messaging to motivate walking in older African Americans: a randomized controlled trial. Am J Prev Med. 2013;44(1):71-5.

57. Mendelson M, Vivodtzev I, Tamisier $\mathrm{R}$, et al. CPAP treatment supported by telemedicine does not improve blood pressure in high cardiovascular risk OSA patients: a randomized, controlled trial. Sleep. 2014;37(11):1863-70.

58. Tabak M, Brusse-Keizer M, van der Valk P, Hermens H, Vollenbroek-Hutten M. A telehealth program for self-management of COPD exacerbations and promotion of an active lifestyle: a pilot randomized controlled trial. Int Chronic Obstruct Pulmon Dis. 2014;9:935.

59. Tabak M, Vollenbroek-Hutten MM, van der Valk PD, van der Palen J, Hermens HJ. A telerehabilitation intervention for patients with chronic obstructive pulmonary disease: a randomized controlled pilot trial. Clin Rehabil. 2014;28(6):582-91.

60. Vroege DP, Wijsman CA, Broekhuizen K, et al. Dose-response effects of a web-based physical activity program on body composition and metabolic health in inactive older adults: additional analyses of a randomized controlled trial. J Med Internet Res. 2014;16(12):e265.

61. Maddison R, Pfaeffli $L$, Whittaker $R$, et al. A mobile phone intervention increases physical activity in people with cardiovascular disease: results from the HEART randomized controlled trial. Eur J Prev Cardiol. 2015; 22(6):701-9.

62. Martin SS, Feldman DI, Blumenthal RS, et al. mActive: a randomized clinical trial of an automated mHealth intervention for physical activity promotion. J Am Heart Assoc. 2015;4(11):e002239.

63. van der Weegen $S$, Verwey $R$, Spreeuwenberg $M$, Tange $H$, van der Weijden T, de Witte L. It's life! Mobile and web-based monitoring and feedback tool embedded in primary care increases physical activity: A cluster randomized controlled trial. J Med Internet Res. 2015;17(7):e184.

64. Broekhuizen K, de Gelder J, Wijsman CA, et al. An internet-based physical activity intervention to improve quality of life of inactive older adults: a randomized controlled trial. J Med Internet Res. 2016:18(4):e74.

65. Müller AM, Hhoo S, Morris T. Text messaging for exercise promotion in older adults from an upper-middle-income country: Randomized controlled trial. J Med Internet Res. 2016:18(1):e5.

66. Demeyer H, Louvaris Z, Frei A, et al. Physical activity is increased by a 12week semiautomated telecoaching programme in patients with COPD: a multicentre randomised controlled trial. Thorax. 2017;72(5):415-23.

67. Lyons EJ, Swartz MC, Lewis ZH, Martinez E, Jennings K. Feasibility and acceptability of a wearable technology physical activity intervention with telephone counseling for mid-aged and older adults: a randomized controlled pilot trial. J Med Internet Res. 2017;19(3):1.

68. Nahm E-S, Resnick B, Brown C, Zhu S, Magaziner J, Bellantoni M, et al. The effects of an online theory-based bone health program for older adults. J Appl Gerontol. 2017;36(9):1117-44.

69. Ellis TD, Cavanaugh JT, DeAngelis T, et al. Comparative effectiveness of mHealth-supported exercise compared with exercise alone for people with Parkinson disease: randomized controlled pilot study. Phys Ther. 2019;99(2):203-16.

70. Rowley TW, Lenz EK, Swartz AM, Miller NE, Maeda H, Strath SJ. Efficacy of an individually tailored, internet-mediated physical activity intervention in older adults: a randomized controlled trial. J Appl Gerontol. 2019;38(7):1011-22.

71. Mouton A, Cloes M. Efficacy of a web-based, center-based or combined physical activity intervention among older adults. Health Educ Res. 2015; 30(3):422-35.

72. Hagstromer M, Ainsworth BE, Oja P, Sjostrom M. Comparison of a subjective and an objective measure of physical activity in a population sample. J Phys Act Health. 2010:7(4):541-50. 
73. Barnett $A$, van den Hoek D, Barnett $D$, Cerin E. Measuring moderateintensity walking in older adults using the ActiGraph accelerometer. BMC Geriatr. 2016;16(1):211.

74. Mathews AE, Laditka SB, Laditka JN, Wilcox S, Corwin SJ, Liu R, et al. Older adults' perceived physical activity enablers and barriers: a multicultural perspective. J Aging Phys Act. 2010;18(2):119-40.

75. Zhang J, Brackbill D, Yang S, Becker J, Herbert N, Centola D. Support or competition? How online social networks increase physical activity: a randomized controlled trial. Prev Med Rep. 2016;4:453-8.

76. Wang F-T, Chan H-L, Hsu M-H, Lin C-K, Chao P-K, Chang Y-J. Thresholdbased fall detection using a hybrid of tri-axial accelerometer and gyroscope. Physiol Meas. 2018;39(10):105002.

77. Brownsell S, Hawley M. Fall detectors: do they work or reduce the fear of falling? Housing Care Support. 2004;7(1):18-24.

\section{Publisher's Note}

Springer Nature remains neutral with regard to jurisdictional claims in published maps and institutional affiliations.

Ready to submit your research? Choose BMC and benefit from:

- fast, convenient online submission

- thorough peer review by experienced researchers in your field

- rapid publication on acceptance

- support for research data, including large and complex data types

- gold Open Access which fosters wider collaboration and increased citations

- maximum visibility for your research: over $100 \mathrm{M}$ website views per year

At BMC, research is always in progress.

Learn more biomedcentral.com/submissions 